\title{
Variables associated with subclinical atherosclerosis among rheumatoid arthritis patients of Gulf Cooperative Council countries
}

Suad Hannawi, MSc, PhD, Haifa Hannawi, MSc, PhD, Fahda Alokaily, MSc, PhD, Issa Al Salmi, MSc, PhD.

\begin{abstract}
الأهداف : تقييم أمراض القلب والأوعية الدموية (CVD) من سماكة الشمائة الشريان

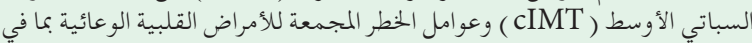

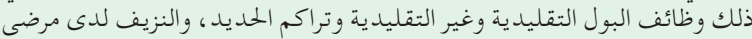

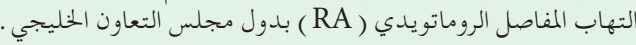

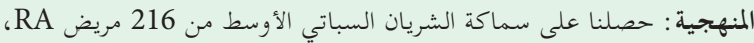

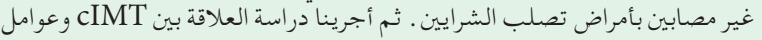

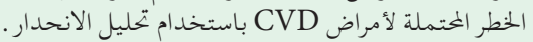

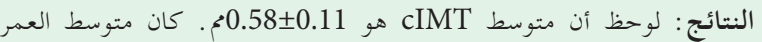

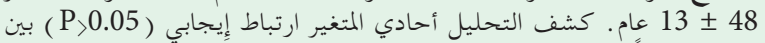

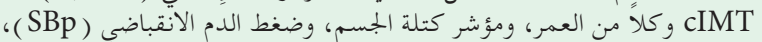

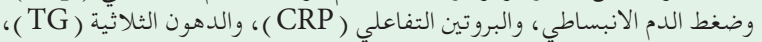

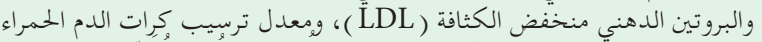

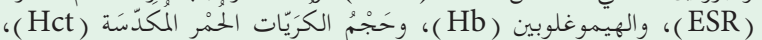

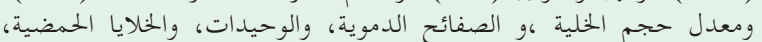

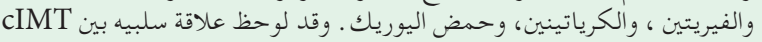

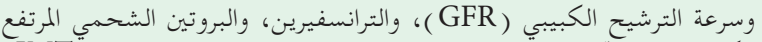

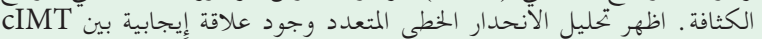

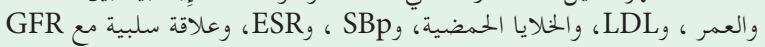

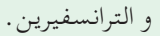

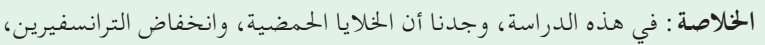

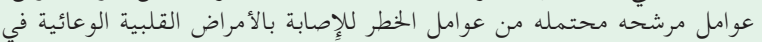

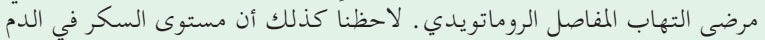

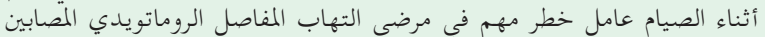

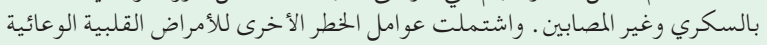

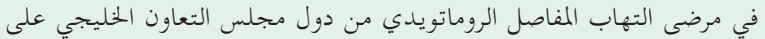

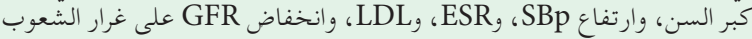

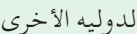

Objectives: To evaluate the cardiovascular disease (CVD) as demonstrated by carotid intima-media thickness (cIMT) and the cluster risk factors of CVD including traditional and non-traditional, urinary functions, iron buildup, and hemorheology in rheumatoid arthritis (RA) patients of Gulf Cooperative Council (GCC) countries.

Methods: Carotid intima-media thickness was obtained from 216 RA patients, free of atherosclerotic diseases. The correlation between cIMT and the possible CVD risk factors was carried out using regression analysis.
Results: The mean cIMT was observed as $0.58 \pm 0.11 \mathrm{~mm}$. Mean age was $48 \pm 13$ years. Univariate analysis revealed a positive association $(p<0.05)$ between cIMT and age, body mass index, systolic blood pressure (SBp), and diastolic blood pressure, c-reactive protein (CRP), triglycerides (TG), low-density lipoprotein (LDL), erythrocyte sedimentation rate (ESR), hemoglobin $(\mathrm{Hb})$, hematocrit (Hct), mean cell volume, platelet, monocytes, eosinophils, ferritin, creatinine, and uric acid. Negative relationship was observed between cIMT and glomerular filtration rate (GFR), transferrin, and high-density lipoprotein. Multiple linear regression analysis exhibited a positive association between cIMT and the age, LDL, eosinophil, SBp, and the ESR, whereas, negative connection with the GFR and transferrin.

Conclusion: In this study, we found that the eosinophils, and low transferrin, are the potential candidates for the CVD risk factors in RA patients. Fasting blood glucose level was also observed to be a significant risk factor in diabetic as well as non-diabetic RA. The remaining CVD risk factors in RA patients of GCC countries including older age, high SBp, ESR, LDL, and low GFR were similar to the international population.

Keywords: carotid intima-media thickness, rheumatoid arthritis, cardiovascular disease, atherosclerosis, inflammation, c-reactive protein, ischemic heart disease

Saudi Med J 2020; Vol. 41 (2): 128-137 doi: 10.15537/smj.2020.2.24900

From the Ministry of Health and Prevention (Hannawi S, Hannawi H), Dubai, United Arab Emirates, from Prince Sultan Military Medical City (Alokaily), Riyadh, Kingdom of Saudi Arabia, and from the Royal Hospital (Al Salmi), Muscat, Oman.

Received 11th December 2019. Accepted 6th January 2020.

Address correspondence and reprint request to: Dr. Suad Hannawi, Medical Department-Al Baraha Hospital, Ministry of Health and Prevention, Dubai, United Arab Emirates. E-mail: suad1@ausdoctors.net ORCID ID: https://orcid.org/0000-0002-2207-5703 
$\mathrm{P}$ atients with rheumatoid arthritis (RA) have an augmented risk of cardiovascular disease (CVD) compared to the general population..$^{1-3}$ In addition to traditional and non-traditional CVD risk factors, the systemic inflammation in RA increases the probabilities of CVD. However, still, there is a gap in the literature about what are the mechanisms involved and how these factors add to the CVD risk. In comparison to the general population, the traditional CVD risk factors behave differently in RA patients. ${ }^{4}$ Possibly, there could be a geographical variation of these risk factors across the globe. Realizing that the pathogenesis of CVD is complex; knowledge about determinants are needed. Therefore, we suggested CVD risk factors that have been identified by other researchers to be related to CVD in general, might contribute to the CVD process in RA. These risk factors include altered hemorheological parameters and iron accumulation. 5

Cardiovascular disease is part of a larger process of atherosclerosis, which is a slowly progressive and diffuse change to the arterial tree. Modern ultrasound techniques are useful for the evaluation of both atherosclerosis-associated anatomical and functional changes. Carotid intima-media thickness (cIMT) is a non-invasive ultrasonic good surrogate marker of the presence of atherosclerosis and probable stages of atherosclerosis. A single cIMT assessment is having similar significance to the frequently used risk factors for the purpose of estimation of CVD and coronary heart disease (CHD). ${ }^{6}$ Furthermore, cIMT measurement could serve as a graded marker for CVD and as a standard marker of the burden of atherosclerosis. ${ }^{7}$

Identifying variable CVD risk factors in relation to RA is of great importance for primary prevention of CVD and therefore reducing associated mortality and morbidity. Hence, the objective of this study was to evaluate the rate of atherosclerosis and its connection with CVD risk factors including traditional and nontraditional, RA inflammatory markers and RA-disease activity scores. Moreover, we also observed the urinary function, iron study, and the hemorheology effect on the cIMT.

Disclosure. Authors have no conflict of interests, and the work was not supported or funded by any drug company. Dr. Fahda Alokaily is a member of the Editorial Team, and was therefore excluded from any final editorial decisions regarding this paper.
Methods. We conducted a cross-sectional study and included 216 patients who completed the European League Against Rheumatism (EULAR) and the American College of Rheumatology (ACR) standards for the classification of RA. ${ }^{8}$ The patients had been recruited through a main tertiary federal hospital in Dubai, United Arab Emirates (UAE) over a period of 5 years (2013-2018).

Compliance with ethical standards. Humans' subjects were involved in the study. All procedures accomplished in the study were according to the ethical values of the institutional and the national research committee and with the 1964 Helsinki declaration and following amendments. The study received ethical approval from the Central Research Ethics Committee of the Ministry of Health and Prevention of the United Arab Emirates. Written ICF was obtained from all participants included in the study.

Medical histories of the patients were recorded by reviewing the electronic files. Information obtained included age, status of rheumatoid factor (RF), rheumatoid factor level (NR: 0.0-14 IU/ml), present medications, co-morbidities (namely, hypertension, diabetes, dyslipidemia, gout, thyroid, and renal illnesses), smoking status (current/past smoking history). Patients were excluded if they had a smoking history, history of CVD, diabetes, hypertension, thyroid, renal disease, gout, patients on diuretics medications, and pregnant women. Hypertension was defined as the use of antihypertensive medications or as recorded blood pressure (BP) $\geq 140 / 90$. Gout was defined as a recorded clinical diagnosis or as the use of hypouricemic agents. Diabetes was defined as the use of diabetic medications (oral or injections) or had been diagnosed with diabetes mellitus. Thyroid disease was defined as the use of thyroid medications or had been diagnosed as a case of thyroid problem (hypo or hyperthyroidism).

Laboratory investigations were carried out within one week of cIMT ultrasound (US) measurement. The patients were subjected to the detailed physical investigation including joints swelling and tenderness. Systolic blood pressure (SBp) and diastolic blood pressure (DBp) were recorded in the right upper arm in a seated position with an automatic oscillometric BP recorder. Standing height and weight were measured to calculate the body mass index (BMI) using the following formula: $\mathrm{BMI}=$ weight $(\mathrm{kg}) /$ height $(\text { meter })^{2}$.

Disease activity scores for 28 joints (DAS-28) were measured using erythrocyte sedimentation rate (ESR), (normal range [NR]: $0.0-30 \mathrm{~mm} /$ hour) and c-reactive protein (CRP), (CRP; $0.0-4.0 \mathrm{mg} / \mathrm{L})$. 
Rheumatoid factor positivity and level obtained using immunoturbidimetric technique (NR: 0.0-14 IU/ml). Fasting blood sample was collected for measurement of fasting glucose level (NR: 4.6-6.4 mmole/L), total cholesterol (NR: 2.0-2.5 mmole/L), low-density lipoprotein (LDL) (NR: 0.0-2.5 mmole/L), highdensity lipoprotein (HDL) (NR: 1.0-1.6 mmole/L), triglycerides (TG) (NR: 0.4-1.9 mmole/L), urea (NR: 0.0-8.3 mmole/L), creatinine (NR: 44-133 $\mu$ mole/L), serum uric acid (SUA) (NR: $155-476 \mu$ mole/L), iron study parameters (iron, ferritin, transferrin), hemorheology, erythrocyte sedimentation rate (ESR), and CRP. Glomerular filtration rate (GFR) was measured by the modification of diet in renal disease equation (MDRD).

Carotid intima-media thickness US measurement. Carotid intima-media thickness US measures acquired through a real-time US scanner, armed with a $7.5 \mathrm{MHz}$ linear probe. All the measurements were recorded by a single sonographer. Patients were positioned in the supine position, with the head turned away opposite to the sonographer, and little extended neck with slight rotation. The length between the intima-luminal interface and the media-adventitial interface was considered as the cIMT and the thickness was recorded in the far wall of both carotid arteries, at a place approximately one $\mathrm{cm}$ proximal to the carotid artery bifurcation. Three were images captured for each side, and the averages of the 6 measures used for statistical applications.

Statistical analysis. Stata 9/SE statistical software (Stata Corp, College Station, Texas, USA) used for statistical analysis. The summary of the statistical analysis results were expressed as percentages for categorical variables, whereas mean $\pm S D$ for continuous variables. Before applying stats, the data for cIMT were logarithmically transformed. The correlation among cIMT and other variables were analyzed using simple linear regression analysis considering cIMT as a dependent variable (outcome). Covariates; independent variables were the traditional CVD risk factors, RA related inflammatory markers (ESR, and CRP), DAS, urinary function, iron study parameters, and hemorheology parameters.

In order to determine whether independent associations present between cIMT and other variables of the study backward multiple linear regression (MLR) models were fitted in the analysis. The multivariate model analysis was performed in a way that included all the independent variables that were significantly associated with the cIMT in the univariate models. A $p<0.05$ was considered statistically significant.
Results. In this study, we included 216 patients. The demographic features and the RA characteristics, iron study and renal function of the participant are listed in Table 1. The average cIMT was found to be $0.58 \pm 0.11 \mathrm{~mm}$ (minimum: 0.28, maximum: 0.98). Whereas, mean age was recorded as $48 \pm 13$ years $(48 \pm 12$ years for females, $50 \pm 16$ years for males, $p=0.279$ ). Rheumatoid factor was found to be positive in 168 (78\%) patients, and the mean RF level was $56 \pm 109$ IU/ $\mathrm{ml}$. The mean ESR was $28.904 \pm 22 \mathrm{~mm} /$ hour, and CRP was $10.116 \pm 25,452 \mathrm{mg} / \mathrm{dL}$. Cardiovascular disease risk factors analysis showed an SBp 126 $\pm 20,526 \mathrm{mmHg}$ and DBp $74.890 \pm 11.341 \mathrm{mmHg}$. Mean BMI was $30.361 \pm 6.316 \mathrm{~kg} / \mathrm{m}^{2}$. The univariate regression analysis (Table 2) exhibited a positive linear association between cIMT and age of the patients $(p=0.001)$, hemoglobin (Hb) $(p=0.006)$, hematocrit (Hct) $(p=0.006)$, mean cell volume (MCV) $(p=0.027)$, mean cell hemoglobin $(\mathrm{MCH}) \quad(p=0.04)$, platelet $(p=0.000)$, monocytes $(p=0.02)$, eosinophils $(p=0.011)$, and ESR $(p=0.04)$. Furthermore, positive linear correlation also observed between cIMT and creatinine $(p=0.002)$, uric acid $(p=0.002)$, TG $(\mathrm{p}=0.033)$, LDL $(p=0.002)$, CRP $(p=0.000)$, ferritin $(p=0.000)$, body weight $(p=0.018)$, BMI ( $\mathrm{p}=0.026)$, SBp $(\mathrm{p}=0.000)$, and DBp $(p=0.001)$. Whereas, transferrin $(p=0.001)$, HDL $(p=0.000)$, GFR $(p=0.024)$ were found with negative linear relationship with cIMT. The data for adjusting confounding variables carried out by comprising all independent variables showing a significant linear correlation with the cIMT in the univariate analysis into a multivariable regression analysis (MLR) are presented in Table 3. The MLR analysis exhibited a positive linear relationship between IMT and age $(p=0.000)$, LDL $(p=0.003)$, eosinophils $(p=0.025), \operatorname{SBp}(p=0.004)$, and the ESR ( $v=0.016)$. In addition to this, the MLR analysis demonstrated a negative linear association between cIMT and GFR $(p=0.02)$, and transferrin $(p=0.000)$. The R2 value of the regression model was found to be 0.65 .

Discussion. Atherosclerotic diseases may remain asymptomatic for many years, but even on the first appearance of symptoms, it becomes fatal and lifethreatening. Therefore, early diagnosis and prevention of atherosclerosis turned out to be essential targets in the field of CVD. Presently the non-invasive B-mode US considered ideal for the screening of CVD. Using US techniques, evidence of increased sub-clinical atherosclerosis in RA subjects has been shown in several studies but the correlation of cIMT and each of urine function parameters, and blood rheology has been explored in only few studies. This study investigated 
Table 1 - Demographic details, rheumatoid arthritis characteristics, iron study, renal function, Carotid intima-media thickness (cIMT) and hemorheology of 216 rheumatoid arthritis (RA) patients.

\begin{tabular}{|c|c|}
\hline Demographic details & Mean \pm SD \\
\hline Male:Female (ratio) & $37: 179$ \\
\hline Age & $48 \pm 13$ \\
\hline Male age & $50 \pm 16$ \\
\hline Female age & $48 \pm 12$ \\
\hline BMI $\left(\mathrm{kg} / \mathrm{Ht}^{2}\right)$ & $30.361 \pm 6.316$ \\
\hline \multicolumn{2}{|l|}{$R A$ characteristics } \\
\hline $\operatorname{ESR}(\mathrm{mm} / \mathrm{hr})$ & $28.904 \pm 22.156$ \\
\hline CRP (mg/dl) & $10.116 \pm 25.452$ \\
\hline DAS-ESR & $5.136 \pm 1.548$ \\
\hline DAS-CRP & $4.451 \pm 1.518$ \\
\hline Tender joint count (of 28) & $15(11)$ \\
\hline Swollen joint count (of 28) & $4 \quad(5)$ \\
\hline Rheumatoid factor level & $56(109)$ \\
\hline Rheumatoid factor positive & $168 \quad(78)$ \\
\hline \multicolumn{2}{|l|}{ Iron study } \\
\hline Ferritin & $70.940 \pm 84.550$ \\
\hline Transferrin & $265.987 \pm 71.836$ \\
\hline Iron & $11.642 \pm 5.390$ \\
\hline \multicolumn{2}{|l|}{ Renal function } \\
\hline Creatinine & $57.677 \pm 18.354$ \\
\hline Uric acid $(\mu \mathrm{mol} / \mathrm{L})$ & $282.322 \pm 91.234$ \\
\hline Urinary protein $(\mathrm{mg} / \mathrm{L})$ & $151.568 \pm 230.392$ \\
\hline GFR (ml/min) & $123.474 \pm 34.711$ \\
\hline Urea & $4.410 \pm 5.243$ \\
\hline \multicolumn{2}{|l|}{ Traditional CVD risk factors } \\
\hline Systolic blood pressure $(\mathrm{mmHg})$ & $126 \pm 20.526$ \\
\hline Diastolic blood pressure $(\mathrm{mmHg})$ & $74.890 \pm 11.341$ \\
\hline Glucose fasting & $7.097 \pm 9.820$ \\
\hline Glycosylated hemoglobin $(\mathrm{mmol} / \mathrm{mol})$ & $6.492 \pm 1.640$ \\
\hline Cholesterol & $4.603 \pm 0.960$ \\
\hline Low-density lipoprotein $(\mathrm{mmol} / \mathrm{L})$ & $2.842 \pm 0.966$ \\
\hline Triglycerides $(\mathrm{mmol} / \mathrm{L})$ & $1.278 \pm 0.753$ \\
\hline High-density lipoprotein $(\mathrm{mmol} / \mathrm{L})$ & $1.332 \pm 0.512$ \\
\hline \multicolumn{2}{|l|}{ Atherosclerosis parameter } \\
\hline Carotid intima-media thickness & $0.579 \pm 0.112$ \\
\hline \multicolumn{2}{|l|}{ Hemorbeology } \\
\hline White cell count $\left(0^{-3} / \mathrm{mcl}\right)$ & $7.338 \pm 2.725$ \\
\hline Hemoglobin $(\mathrm{g} / \mathrm{dl})$ & $12.371 \pm 1.681$ \\
\hline Hematocrit & $38.232 \pm 4.769$ \\
\hline Mean cell volume & $83.837 \pm 8.605$ \\
\hline Mean cell hemoglobin & $27.334 \pm 4.113$ \\
\hline Platelet & $271.424 \pm 76.402$ \\
\hline Monocyte $\left(10^{-3} / \mathrm{mcl}\right)$ & $7.716 \pm 2.511$ \\
\hline Lymphocyte $\left(0^{-3} / \mathrm{mcl}\right)$ & $34.471 \pm 10.718$ \\
\hline Basophil $\left(0^{-3} / \mathrm{mcl}\right)$ & $2.687 \pm 1.831$ \\
\hline Neutrophil $\left(0^{-3} / \mathrm{mcl}\right)$ & $54.778 \pm 12.160$ \\
\hline Eosinophil $\left(10^{-3} / \mathrm{mcl}\right)$ & $2.687 \pm 1.831$ \\
\hline \multicolumn{2}{|c|}{$\begin{array}{l}\text { Values are presented as numbers and percentages (\%). RA: rheumatoid } \\
\text { arthritis, BMI: body mass index, ESR: erythrocyte sedimentation rate, } \\
\text { CRP: c-reactive protein, DAS: disease activity score, GFR: glomerular } \\
\text { filtration rate }\end{array}$} \\
\hline
\end{tabular}

the cIMT in RA patients of the GCC population, and none of them observed at each of traditional, inflammatory markers, disease activity score, urinary functions, iron status, and blood rheology in the same group of RA investigated the cIMT in RA patients of the GCC population, and none of them observed at each of traditional, inflammatory markers, disease activity score, urinary functions, iron status, and blood rheology in the same group of RA.

Carotid intima-media thickness and age of $R A$ patients. Our results showed a linear positive correlation with the RA patients' age and the cIMT. This finding agrees with many previous reports that showed the effect of the age of RA patients on cIMT. ${ }^{3}$ Multivariate modeling indicated that a sizeable age-related effect remained, in addition to many traditional and nontraditional CVD risk factors. Therefore, it is likely that increased cIMT is not merely an isolated age effect. Although age is not amenable to RA treatment; however, many other risk factors associated with age could be altered and modified by available medications.

Carotid intima-media thickness, $\mathrm{Hb}, \mathrm{Hct}$, and MCV. Complete blood count (CBC) and hemorheological parameters symbolize valuable, economical, and extensively accessible laboratory tools. Interestingly, $\mathrm{CBC}$ and hemorheological parameters have been reported as good measures for assessing the management and prognosis of various CVD including CHD, heart failure (HF), stroke, arrhythmias, and hypertension. ${ }^{9}$

Several studies evaluated the relationship between $\mathrm{CVD}$ and each of $\mathrm{Hb}$ and Hct level. These studies have made known that anemia (low $\mathrm{Hb}$ concentration) and polycythemia (high $\mathrm{Hb}$ concentration) are autonomous CVD risk factors in the common populace. ${ }^{10-12}$ Others reported that low or high $\mathrm{Hb}$ levels are related to raised CVD and all-cause mortality. Whereas attaining and maintaining $\mathrm{Hb}$ levels in the standard range reported to reduce the all-cause mortality. Smith et al, ${ }^{13}$ reported a positive connection between $\mathrm{Hb}$ concentration and traditional CVD risk factors including total cholesterol, fasting glucose, smoking status, BMI, and BP, after the adjustment for age. The relationship between $\mathrm{Hb}$ and CVD persisted even after the fine-tuning of data for these traditional CVD risk factors. ${ }^{13}$

Similarly, either low or high Hct (percentage of red blood cells) levels are associated with an increased CVD risk. ${ }^{3}$ Some studies found elevated Hct as a predictor of atherosclerosis incidence, unstable angina, and myocardial infarction as an independent risk of CVD morbidity and mortality. ${ }^{15,16}$ The Framingham Heart Study described the association between high Hct and CVD occurrence in females after adjusting for multiple CVD risk factors. ${ }^{17}$

Increased $\mathrm{Hb}$ or Hct level results in augmented blood viscidness and blood thickness. The elevated 
Table 2 - Multivariatelinear regression analysis of the relationship between cIMT, selected RA features, traditional CV risk factors, urinary parameters and hemorheologyin 2016 patients with RA.

\begin{tabular}{|c|c|c|c|c|c|c|}
\hline Variables & $\mathbf{R}^{2}$ & $\beta$ coefficient & $\begin{array}{c}\text { Standard } \\
\text { error }\end{array}$ & $\mathrm{t}$ & $P$-value & Confidence interval \\
\hline Age, (years) & 0.33 & 0.005 & 0.000 & 10.04 & 0.000 & $0.004-0.006$ \\
\hline Systolic blood pressure $(\mathrm{mmHg})$ & 0.11 & 0.002 & 0.000 & 4.62 & 0.000 & $0.001-0.003$ \\
\hline Diastolic blood pressure $(\mathrm{mmHg})$ & 0.06 & 0.002 & 0.001 & 3.29 & 0.000 & $0.001-0.004$ \\
\hline RBC (10 (6)/mcL) & 0.00 & 0.011 & 0.014 & 0.75 & 0.457 & $-0.018-0.039$ \\
\hline Hemoglobin (g/dl) & 0.05 & 0.014 & 0.005 & 2.79 & 0.006 & $0.004-0.024$ \\
\hline $\mathrm{MCH}(\mathrm{pg})$ & 0.02 & 0.005 & 0.002 & 2.02 & 0.040 & $0.000-0.009$ \\
\hline MCV (fL) & 0.03 & 0.002 & 0.001 & 2.23 & 0.027 & $0.000-0.004$ \\
\hline Hct $(\%)$ & 0.04 & 0.005 & 0.002 & 2.77 & 0.003 & 0.001-0.009 \\
\hline MCV (fL) & 0.03 & 0.002 & 0.001 & 2.23 & 0.027 & $0.000-0.004$ \\
\hline Platelet (10 (3)/mcL) & 0.07 & -0.000 & 0.000 & -3.64 & 0.000 & $-0.001-0.000$ \\
\hline WCC (10 (3)/mcL) & 0.02 & 0.005 & 0.003 & 1.68 & 0.095 & $-0.001-0.010$ \\
\hline Neutrophil (10 (3)/mcL) & 0.00 & -0.000 & 0.001 & -0.72 & 0.475 & $-0.002-0.001$ \\
\hline Lymphocyte (10 (3)/mcL) & 0.00 & 0.000 & 0.001 & 0.08 & 0.938 & $-0.001-0.001$ \\
\hline Monocyte(10 (3)/mcL) & 0.03 & 0.010 & 0.004 & 2.29 & 0.023 & 0.001-0.019 \\
\hline Eosinophil $(10(3) / \mathrm{mcL}))$ & 0.04 & 0.011 & 0.004 & 2.57 & 0.011 & $0.002-0.019$ \\
\hline Basophil (10 (3)/mcL) & 0.01 & 0.006 & 0.028 & 0.22 & 0.823 & $-0.049-0.061$ \\
\hline Weight measured (kg) & 0.03 & 0.001 & 0.000 & 2.39 & 0.018 & $0.000-0.002$ \\
\hline Body mass index $\left(\mathrm{kg} / \mathrm{ht}^{2}\right)$ & 0.03 & 0.003 & 0.001 & 2.26 & 0.026 & $0.004-0.006$ \\
\hline $\operatorname{ESR}(\mathrm{mm} / \mathrm{hr})$ & 0.02 & 0.001 & 0.000 & 2.01 & 0.040 & $0.000-0.001$ \\
\hline CRP (mg/dl) & 0.08 & 0.001 & 0.000 & 3.95 & 0.000 & $0.001-0.002$ \\
\hline Creatinine (mmol/L) & 0.05 & 0.001 & 0.000 & 3.14 & 0.002 & $0.000-0.002$ \\
\hline Uric acid $((\mu \mathrm{mol} / \mathrm{L})$ & 0.05 & 0.000 & 0.000 & 3.15 & 0.002 & $0.000-0.001$ \\
\hline Urinary protein $(\mathrm{mg} / \mathrm{L})$ & 0.23 & 0.000 & 0.000 & 5.11 & 0.000 & $0.000-0.001$ \\
\hline GFR (ml/min) & 0.03 & -0.001 & 0.000 & -2.28 & 0.024 & $-0.001--0.000$ \\
\hline $\mathrm{LDL}(\mathrm{mmol} / \mathrm{L})$ & 0.06 & 0.028 & 0.009 & 3.15 & 0.002 & $0.010-0.045$ \\
\hline $\mathrm{HDL}(\mathrm{mmol} / \mathrm{L})$ & 0.09 & -0.070 & 0.017 & -4.09 & 0.000 & $-0.103--0.036$ \\
\hline Cholesterol & 0.01 & 0.004 & 0.009 & 0.41 & 0.684 & $-0.021-0.014$ \\
\hline Triglyceride (mmol/L) & 0.03 & 0.023 & 0.011 & 2.15 & 0.033 & $0.002-0.044$ \\
\hline Glucose fasting $(\mathrm{mmol} / \mathrm{L})$ & 0.02 & 0.001 & 0.001 & 1.71 & 0.080 & $-0.000-0.003$ \\
\hline Iron (unit) & 0.01 & 0.000 & 0.002 & 0.11 & 0.091 & $-0.004-0.004$ \\
\hline Ferritin (mcg/L) & 0.13 & 0.000 & 0.000 & 4.06 & 0.000 & $0.000-0.001$ \\
\hline Transferrin (mg/dl) & 0.12 & -0.001 & 0.000 & -3.53 & 0.001 & $-0.001--0.000$ \\
\hline $\begin{array}{l}\text { RA: rheumatoid arthritis, cIN } \\
\text { MCH: mean cell hemoglobin } \\
\text { sedimentation rate, CRP - C-r }\end{array}$ & $\begin{array}{l}\text { otid i } \\
\text { : mea }\end{array}$ & $\begin{array}{l}\text { edia thicknes } \\
\text { lume, Hct: } \mathrm{h} \\
\text { - glomerular } \\
\text { density lipop }\end{array}$ & $\begin{array}{l}\text { V: cardiov } \\
\text { tocrit }(\%) \\
\text { tion rate, } \\
\text { n. }\end{array}$ & $\begin{array}{l}\text { lar, RB } \\
\text { CC: w } \\
\text { L - low }\end{array}$ & $\begin{array}{l}\text { d blood } \\
\text { ell coun } \\
\text { ity lipor }\end{array}$ & $\begin{array}{l}\text { ell }(10(6) / \mathrm{mcL}) \\
\text { ESR: erythrocyte } \\
\text { otein, HDL - high }\end{array}$ \\
\hline
\end{tabular}

Table 3 - Multivariate linear regression analysis of the relationship between cIMT, selected RA features, traditional CV risk factors, urinary parameters and hemorheologyin 216 patients with RA.

\begin{tabular}{lccccc}
\hline Variables & $\beta$ coefficient & SE & $\mathbf{t}$ & $\boldsymbol{P}$-value & CI \\
\hline Age, (years) & 0.004 & 0.001 & 5.28 & 0.000 & $0.003-0.006$ \\
Systolic blood pressure (mmHg) & 0.002 & 0.001 & 3.00 & 0.004 & $0.001-0.003$ \\
LDL (mmol/L) & 0.033 & 0.010 & 3.19 & 0.003 & $0.012-0.053$ \\
Glucose fasting (mmol/L) & 0.010 & 0.005 & 2.20 & 0.033 & $0.001-0.020$ \\
ESR (mm/hr) & 0.001 & 0.001 & 2.51 & 0.016 & $0.002-0.008$ \\
Eosinophil (10 (3)/mcL) & 0.013 & 0.005 & 2.32 & 0.025 & $0.002-0.023$ \\
Transferrin (mg/dl) & -0.001 & 0.000 & -4.24 & 0.000 & $-0.001--0.000$ \\
GFR (ml/min) & -0.001 & 0.000 & -2.38 & 0.022 & $-0.001--0.000$ \\
\hline RA - rheumatoid arthritis, cIMT - carotid intima media thickness, CV - cardiovascular, SE - standard error, CI \\
- confidence interval, LDL - low density lipoprotein, ESR - erythrocyte sedimentation rate, GFR - glomerular \\
filtration rate.
\end{tabular}


blood thickness alters blood circulation, consequently increasing peripheral resistance which leads to slow blood circulation to the organs as well as slow oxygenation. ${ }^{18,19}$ Furthermore, it upsurges atherogenesis, stimulates plaque rupture, and thus finally leads to ischemia. ${ }^{20}$ Moreover, elevated Hct level triggers platelet activation as well as oxidative stress phenomenon by discharging adenosine diphosphate (ADP) in reaction to iron build up. $^{21}$

In addition to the $\mathrm{Hb}$ and Hct levels, the mean corpuscular volume (MCV) has been reported to be correlated with CVD risk in a variety of populations. ${ }^{22,23}$ Our study extending the knowledge about hemorheology alteration as a CVD risk in RA patients. Our results showed a positive correlation between the $\mathrm{Hb}$ concentration, Hct level, and MCV with CVD as manifested by cIMT for the first time in the RA population. The combination of $\mathrm{Hb}, \mathrm{Hct}$, MCV levels, and CVD risk may empower the ability for timely detection of CVD.

Carotid intima-media thickness and platelet. Platelets are another component of hemorheology that has been investigated as a cause and as a marker of CVD. Platelet count has been reported to be linked with CVD deaths in a population-based cohort study. ${ }^{24}$ On the other hand, platelet functional abnormality has also been studied. Subjects with an ischemic heart ailment and with coronary artery disease (CAD) risk factors are reported to have abnormal and sensitive platelets. ${ }^{25}$ Therefore, it can be established that platelet aggregation and endothelial damage are associated with the etiology of atherosclerosis. Products discharged from platelets through the accumulation process may trigger arterial spasm. ${ }^{25}$ Our study revealed that platelet count is connected with cIMT in a positive linear design, supporting a possible role for platelets in CVD.

Carotid intima-media thickness and white cell count (cIMT and monocytes). Several studies have stated that an elevated leukocyte count is a robust and impartial CVD risk factor. ${ }^{26,27}$ In other studies, monocyte count confirmed to be correlated with the incidence and development of subclinical cIMT, to foresee the untimely manifestation of a coronary incidence, to be related to BMI, clustering of metabolic syndrome, CVD history, atherosclerotic plaque instability and rupture, and that particular monocyte sub-classes control hypercholesterolemia-related monocytosis and produce precisely to macrophages in atheroma. ${ }^{28-35}$ Monocyte and monocyte-originated macrophages impart a vital role in the initial stage of atherogenesis and the progression of atherosclerosis. ${ }^{36,37}$ Olivares et $\mathrm{al}^{31}$ reported that the risk of coronary heart disease rose 1.15 times if there was an increase of 100 cells $/ \mathrm{mm}^{3}$ in monocyte count. Following previously published results, our results emphasize the significant correlation between the monocytes and cIMT. Moreover, our study extends this relation to apply to the CVD risk among RA patients.

Carotid intima-media thickness and eosinophils. Prentice et $a{ }^{38}$ reported a similar relation between CVD and other parameters of white cell count (WCC); eosinophil and neutrophils count. Eosinophil count and the ratio of eosinophil to leukocyte has been materialized as unique biomarkers in CAD patients for risk classification in patients with CAD. Eosinophils impart a key role in vasoconstriction, endothelial malfunction, thrombosis, and swelling. ${ }^{39,40}$ Other studies demonstrated that eosinophils are connected with coronary artery calcification, stent restenosis, slow coronary flow, stent thrombosis and acute coronary disorders. ${ }^{41}$

On the other hand, there is a published report claiming that elevated eosinophils level is not autonomously correlated with the incidence and magnitude of CAD. However, chances are more that it is linked with the most important cardiovascular risk factors. ${ }^{42}$

The cIMT in our RA groups was significantly associated with the eosinophils count in the univariate linear regression. This relationship was found to be maintained even when adjusted for the other CVD confounding factors in the multivariate analysis.

Carotid intima-media thickness and iron status. Iron is vital for numerous metabolic pathways and physiological processes. The maintenance of iron homeostasis is essential, and an increase or a decrease in its level can be harmful to the human body. Iron overload has been identified as a CVD risk factor. ${ }^{43}$

Transferrin is a blood-plasma glycoprotein that transports iron through the blood to various tissues, while ferritin is an iron-storage marker and has a role in iron distribution, propagation, angiogenesis, and as well as in immune-suppression. ${ }^{44}$ The synthesis of ferritin which serves as an acute-stage protein is initiated by cytokines, and this could be the reason for its increased levels in diseases involving inflammation. ${ }^{45}$ Although some studies reported a positive association between elevated ferritin levels with CVD, and cIMT $^{46,47}$ Ferritin level $\geq 200 \mathrm{mg} / \mathrm{L}$ reported being associated with a 2.2 times rise in the probability of acute myocardial infarction even when adjusted for additional risk factors. ${ }^{48}$ However, there are few reports failed to demonstrate any connection between ferritin concentrations and CVD. 49,50 These conflicting results of ferritin association with CVD could be explained by 
large variability in iron stores estimates, which included serum iron, serum ferritin, serum transferrin, and the diverse methods in the diagnosis of atherosclerosis. ${ }^{51,52}$

Our study results agree to the concept of increased risk of CVD with excess iron overload as it is showing a positive and linear association between cIMT and ferritin, as well as transferrin levels. The association with the transferrin had been maintained in the MLR after adjustment with the additional CVD risk factors. This is the first study of its kind to show this finding in RA patients The positive association is supported by the capability of iron accumulation to catalyze the creation of free radicals and a reduction of antioxidant levels in plasma through the promotion of lipid peroxidation. Oxidized LDL enhances lipid accumulation in the arterial endothelial and smooth cells, and stops macrophages from exiting the arterial wall. Thus, promote atherosclerosis and increases the risk of ischemic cardiovascular events. ${ }^{43,53,54}$

The sensitive, rapid, validated, and inexpensive assay makes ferritin and transferrin a possible future CVD biomarker, with potential implications for public health. These findings require further investigation in a more extensive multi-center study.

Carotid intima-media thickness and renal function. Sub-clinical renal abnormalityis prevalentin RA and acquaintances with CVD risk..$^{55,56}$ We have reported that sub-clinical renal activity in concurrence with the traditional along with non-traditional CVD risk factors affects combinedly to hasten atherosclerosis in RA patients.Additionally, GFR has a strong relationship with many traditional and non-traditional CVD risks in the RA population..$^{57}$ Furthermore, the presence of SUA in atherosclerotic plaques is considered to play a significant role in the manifestation of atherosclerosis. ${ }^{58}$ Moreover, we demonstrated previously of a positive linear association among SUA and cIMT in RA. ${ }^{59}$ However, other investigators reported that SUA is associated with many CVD risk factors including diabetes mellitus, hypertension, hyperlipidemia and obesity. ${ }^{59-62}$ The data of this study confirms our previous report that the sub-clinical renal function and the SUA lead to cardiovascular risk in RA.

Carotid intima-media thickness and traditional CVD risk factors $T G, L D L, H D L$, and BMI. Kroot et $\mathrm{al},{ }^{63}$ found that hypertension is the most frequently reported co-morbid conditioning RA, followed by angina pectoris. Different mechanisms have been postulated to explain increased atherosclerosis in RA. One hypothesis is related to the co-integration observed between RA and traditional cardiovascular risk factors. ${ }^{64}$
This integration might be evident in our study that showed cIMT is positively affected by the level of LDL and TG level and negatively with the HDL level. In addition to this, BP parameters, SBp and DBp; which are the significant determinants of arterial stiffness, showed to be positively associated with cIMT.

Several reports are available, mentioning that BMI some how influences the development and progression of RA. ${ }^{4}$ There are inconsistent results about the high BMI effect on CVD; some reports suggested an augmented CVD risk in obese persons; however, others reported no such correlation to exist. ${ }^{65,66}$ Nevertheless, most studies indicated that obesity and RA have a positive correlation especially in women ${ }^{67}$ In our study, we found a mean BMI as 30.316 (class 1 obesity), which can be attributed to the sedentary lifestyle of RA patients. The majority of our sample were female (83\%). Our results are following the positive linear association between BMI and cIMT.

The reported results of this study about lipid profile, hypertension, and BMI with the CIMT, support many preceding publications, including our previous studies on RA patients. ${ }^{1,3,59,68}$

The results of the current study stress the concept of regular screening and rigorous management of hypertension, dyslipidemia, traditional cardiovascular risk factors. Additionally, the control of the inflammation is also essential as it synergistically augments the traditional CVD risks in RA patients.

Carotid intima-media thickness and inflammatory markers (ESR and CRP). Inflammation plays a crucial role in RA, and several newlines of evidence suggested that atherosclerosis has an essential inflammatory component. ${ }^{69}$ The concept that inflammatory mediators are actively involved in the progression of vascular damage in RA. These findings are also supported by our study results, which demonstrated a positive and linear correlation amid cIMT and each of the CRP and ESR.

There is a necessary implication of this link, a significant portion of the risk for CVD contained in the inflammatory markers, particularly the CRP and the ESR, can be diagnosed, and the effects of interventions possibly monitored through anti-rheumatic medication. Besides, a large portion of the excess risk from CVD might be alleviated by interventions that reduce inflammation.

One strength of this study was the repetitive measurements of the far wall of left and right carotid arteries, so the chances of errors were high. Therefore, to minimize the reader's bias, variability, and noise we utilized selected and specific software for the automatic 
measurement of cIMT. ${ }^{70}$ Another strength was that we selected the far wall portion of the left and right carotid artery to measure as this segment was easy to approach and suitable for rhythmic measurements. Another strength of this study was the bigger sample size and the exclusion of participants with other diseases, and patients with smoking history.

Study limitations. The drawback of this study was that it was performed mainly on women (83\% of the study sample), and consequently, the study results cannot be extrapolated to the male population. The opted design of the study was cross-sectional, which is well known for its process limitations. Further randomized studies with large sample size and with an equal proportion of males and females are needed to establish the cIMT as a screening for atherosclerosis in RA.

In conclusion, our findings suggest that attention should be given to the risks of CVD in RA patients in the GCC region. The presence and severity of inflammation as cardiovascular risk factors should be considered and treated, in addition to trying to correct the known modifiable cardiovascular traditional risk factors. Furthermore, attention shall be paid to subclinical renal impairment and alternation in iron status and hemorheology.

\section{References}

1. Hannawi S, Hannawi H, Alokaily F, Naredo E, Moller I, Al Salmi I. Recent-onset of rheumatoid arthritis leads to increase in wall thickness of left anterior descending coronary artery. An evidence of subclinical CAD. Saudi Med J 2018; 39: 1213-1217.

2. Carroll L, Hannawi S, Marwick T, Thomas R. Rheumatoid arthritis: links with cardiovascular disease and the receptor for advanced glycation end products. Wien Med Wochenschr 2006; 156: 42-52.

3. Hannawi S, Haluska B, Marwick TH, Thomas R. Atherosclerotic disease is increased in recent-onset rheumatoid arthritis: a critical role for inflammation. Arthritis Res Ther 2007; 9: R116.

4. Charles-Schoeman C. Cardiovascular disease and rheumatoid arthritis: an update. Curr Rheumatol Rep 2012; 14: 455-462.

5. Zanazzi M, Fatini C, Farsetti S, rosso G, Caroti L, Sticchi E, et al. Blood rheology and renal transplantation: an intriguing relationship for assessing cardiovascular risk. Transplant Proc 2010; 42: 1383-1384.

6. del Sol AI, Moons KG, Hollander M, Hofman A, Koudstaal PJ, Grobbee DE, et al. Is carotid intima-media thickness useful in cardiovascular disease risk assessment? Stroke 2001; 32: 1532-1538.

7. Bots ML, Hofman A, Grobbee De. Increased common carotid intima-media thickness. Adaptive response or a reflection of atherosclerosis? Findings from the Rotterdam study. Stroke 1997; 28: 2442-2447.
8. Aletaha D, Neogi T, Silman AJ, Funovits J, Felson DT, Bingham CO, et al. American College of Rheumatology 2010 Rheumatoid Arthritis Classification Criteria An American College of Rheumatology/European League Against Rheumatism Collaborative Initiative Arthritis \& Rheumatism collaborative initiative. Arthritis Rheum 2010; 62: 2569-2581.

9. Mozos I. Mechanisms linking red blood cell disorders and cardiovascular diseases. Biomed Res Int 2015; 2015: 682054.

10. Sarnak MJ, Tighiouart H, Manjunath G, MacLeod B, Griffith J, Salem D, et al. Anemia as a risk factor for cardiovascular disease in The Atherosclerosis Risk in Communities (ARIC) study. J Am Coll Cardiol 2002; 40: 27-33.

11. Kunnas T, Solakivi T, Huuskonen K, Kalela A, Renko J, Nikkari ST. Hematocrit and the risk of coronary heart disease mortality in the TAMRISK study, a 28-year follow-up. Prev Med 2009; 49: 45-47.

12. Barbui T, Finazzi G. Therapy for polycythemia vera and essential thrombocythemia is driven by the cardiovascular risk. Semin Thromb Hemost 2007; 33: 321-329.

13. Smith S, Julius S, Jamerson K, Amerena J, Schork N. Hematocrit levels and physiologic factors in relationship to cardiovascular risk in Tecumseh, Michigan. J Hypertens 1994 12: 455-462.

14. Gotoh S, Hata J, Ninomiya T, Hirakawa Y, Nagata M, Mukai $\mathrm{N}$, et al. Hematocrit and the risk of cardiovascular disease in a Japanese community: The Hisayama study. Atherosclerosis 2015; 242: 199-204.

15. Paul L, Jeemon P, Hewitt J, McCallum L, Higgins P, Walters M, et al. Hematocrit predicts long-term mortality in a nonlinear and sex-specific manner in hypertensive adults. Hypertension 2012; 60: 631-638.

16. Li G, Hu H, Shi W, Li Y, Liu L, Chen Y et al. Elevated hematocrit in nonalcoholic fatty liver disease: a potential cause for the increased risk of cardiovascular disease? Clin Hemorheol Microcirc 2012. 51: 59-68.

17. Gagnon DR, Zhang TJ, Brand FN, Kannel WB. Hematocrit and the risk of cardiovascular disease--the Framingham study: a 34-year follow-up. Am Heart J 1994; 127: 674-682.

18. Finch CA, Lenfant C. Oxygen transport in man. N EnglJ Med 1972; 286: 407-415.

19. Burch GE and DePasquale NP. Hematocrit, viscosity and coronary blood flow. Dis Chest 1965; 48: 225-232.

20. Tikhomirova IA, Oslyakova AO, Mikhailova SG. Mikhailova, Microcirculation and blood rheology in patients with cerebrovascular disorders. Clin Hemorheol Microcirc 2011; 49: 295-305.

21. Lowe GD, Forbes CD. Platelet aggregation, haematocrit, and fibrinogen. Lancet 1985; 1: 395-396.

22. Lassale C, Curtis A, Abete I, van der Schouw YT, Verschuren WMM, Lu Y, et al. Elements of the complete blood count associated with cardiovascular disease incidence: Findings from the EPIC-NL cohort study. Sci Rep 2018; 8: 3290.

23. Carter C, McGee D, Reed D, Yano K, Stemmermann G. Hematocrit and the risk of coronary heart disease: the Honolulu Heart Program. Am Heart J 1983; 105: 674-679.

24. Vinholt PJ, Hvas AM, Frederiksen H, Bathum L, Jørgensen MK, Nybo M. Platelet count is associated with cardiovascular disease, cancer and mortality: A population-based cohort study. Thromb Res 2016; 148: 136-142.

25. Haft JI. Role of blood platelets in CAD. Am J Cardiol 1979; 43: 1197-1206. 
26. Kannel WB, Anderson K, Wilson PW. White blood cell count and cardiovascular disease. Insights from the Framingham Study. JAMA 1992; 267: 1253-1256.

27. Kavousi M, Elias-Smale S, Rutten JH, Leening MJ, Vliegenthart R, Verwoert GC, et al. Evaluation of newer risk markers for coronary heart disease risk classification: a cohort study. Ann Intern Med 2012; 156: 438-444.

28. Nozawa N, Hibi K, Endo M, Sugano T, Ebina T, Kosuge M, et al. Association between circulating monocytes and coronary plaque progression in patients with acute myocardial infarction. Circ J 2010; 74: 1384-1391.

29. Loimaala A, Rontu R, Vuori I, Mercuri M, Lehtimäki T, Nenonen A, et al. Blood leukocyte count is a risk factor for intima-media thickening and subclinical carotid atherosclerosis in middle-aged men. Atherosclerosis 2006; 188: 363-369.

30. Ortega E, Gilabert R, Nuñez I, Cofán M, Sala-Vila A, de Groot $\mathrm{E}$, et al. White blood cell count is associated with carotid and femoral atherosclerosis. Atherosclerosis 2012; 221: 275-281.

31. Olivares R, Ducimetiere P, Claude JR. Monocyte count: a risk factor for coronary heart disease? Am J Epidemiol 1993; 137: 49-53.

32. Sweetnam PM, Thomas HF, Yarnell JW, Baker IA, Elwood PC. Total and differential leukocyte counts as predictors of ischemic heart disease: the Caerphilly and Speedwell studies. Am J Epidemiol 1997; 145: 416-421.

33. Tsai JC, Sheu SH, Chiu HC, Chung FM, Chang DM, Chen $\mathrm{MP}$, et al. Association of peripheral total and differential leukocyte counts with metabolic syndrome and risk of ischemic cardiovascular diseases in patients with type 2 diabetes mellitus. Diabetes Metab Res Rev 2007; 23: 111-118.

34. Kim KI, Lee J, Heo NJ, Kim S, Chin HJ, Na KY, et al. Differential white blood cell count and all-cause mortality in the Korean elderly. Exp Gerontol 2013; 48: 103-108.

35. Falk E. Pathogenesis of atherosclerosis. J Am Coll Cardiol 2006; 47: C7-C12.

36. Gerrity RG. The role of the monocyte in atherogenesis: I. Transition of blood-borne monocytes into foam cells in fatty lesions. Am J Pathol 1981; 103: 181-190.

37. Gerrity RG. The role of the monocyte in atherogenesis: II. Migration of foam cells from atherosclerotic lesions. Am J Pathol 1981; 103: 191-200.

38. Prentice RL, Szatrowski TP, Fujikura T, Kato H, Mason MW, Hamilton HH. Leukocyte counts and coronary heart disease in a Japanese cohort. Am J Epidemiol 1982; 116: 496-509.

39. Sasano H, Virmani R, Patterson RH, Robinowitz M, Guccion JG. Eosinophilic products lead to myocardial damage. Hum Pathol 1989; 20: 850-857.

40. Wang JG, Mahmud SA, Thompson JA, Geng JG, Key NS, Slungaard A. The principal eosinophil peroxidase product, HOSCN, is a uniquely potent phagocyte oxidant inducer of endothelial cell tissue factor activity: a potential mechanism for thrombosis in eosinophilic inflammatory states. Blood 2006; 107: 558-565.

41. Tanaka M, Fukui M, Tomiyasu K, Akabame S, Nakano K, Yamasaki $\mathrm{M}$ et al. Eosinophil count is positively correlated with coronary artery calcification. Hypertens Res 2012; 35 : 325-328.

42. Verdoia M, Schaffer A, Cassetti E, Di Giovine G, Marino P, Suryapranata H, et al. Absolute eosinophils count and the extent of CAD: a single centre cohort study. J Thromb Thrombolysis 2015; 39: 459-466.
43. Kiechl S, Willeit J, Egger G, Poewe W, Oberhollenzer F. Body iron stores and the risk of carotid atherosclerosis: prospective results from the Bruneck study. Circulation 1997; 96: 3300-3307.

44. Watt RK. The many faces of the octahedral ferritin protein. Biometals 2011; 24: 489-500.

45. Khan A, Khan WM, Ayub M, Humayun M, Haroon M. Ferritin is a marker of inflammation rather than iron deficiency in overweight and obese people. J Obes 2016; 2016: 1937320.

46. Knovich MA, Storey JA, Coffman LG, Torti SV. Ferritin for the clinician. Blood Rev 2009; 23: 95-104.

47. Auer J, Rammer M, Berent R, Weber T, Lassnig E, Eber B. Body iron stores and coronary atherosclerosis assessed by coronary angiography. Nutr Metab Cardiovasc Dis 2002; 12: 285-290.

48. Salonen JT, Nyyssönen K, Korpela H, Tuomilehto J, Seppänen $\mathrm{R}$, Salonen R. High stored iron levels are associated with excess risk of myocardial infarction in eastern Finnish men. Circulation 1992; 86: 803-811.

49. Knuiman MW, Divitini ML, Olynyk JK, Cullen DJ, Bartholomew HC. Serum ferritin and cardiovascular disease: a 17-year follow-up study in Busselton, Western Australia. Am J Epidemiol 2003; 158: 144-149.

50. Sun Q, Ma J, Rifai N, Franco OH, Rexrode KM, Hu FB. Excessive body iron stores are not associated with risk of coronary heart disease in women. J Nutr 2008; 138: 2436-2441.

51. Armaganijan D, Batlouni M. Serum ferritin levels and other indicators of organic iron as risk factors or markers in CAD. Rev Port Cardiol 2003; 22: 185-195.

52. Eftekhari MH, Mozaffari-Khosravi H, Shidfar F, Zamani A. Relation between body iron status and cardiovascular risk factors in patients with cardiovascular disease. Int J Prev Med 2013; 4: 911-916.

53. Meyers DG. The iron hypothesis: does iron play a role in atherosclerosis? Transfusion 2000; 40: 1023-1029.

54. de Valk B, Marx JJ. Iron, atherosclerosis, and ischemic heart disease. Arch Intern Med 1999; 159: 1542-1548.

55. Boers M, Dijkmans BA, Breedveld FC, Camps JA, Chang $\mathrm{PC}$, van Brummelen $\mathrm{P}$, et al. Subclinical renal dysfunction in rheumatoid arthritis. Arthritis Rheum 1990; 33: 95-101.

56. Daoussis D, Panoulas VF, Antonopoulos I, John H, Toms TE, Wong P, et al. Cardiovascular risk factors and not disease activity, severity or therapy associate with renal dysfunction in patients with rheumatoid arthritis. Ann Rheum Dis 2010; 69: 517-521.

57. Hannawi S, Al Salmi I. In rheumatoid arthritis, traditional and non traditional cardiovascular risk factgors work collectively to determine renal function. Int J Curr Res 2017; 9: 44946-44951.

58. Patetsios P, Song M, Shutze WP, Pappas C, Rodino W, Ramirez $\mathrm{JA}$, et al. Identification of uric acid and xanthine oxidase in atherosclerotic plaque. Am J Cardiol 2001; 88: 188-191.

59. Hannawi S, AlSalmi I, Moller I, Naredo E. Uric acid is independent cardiovascular risk factor, as manifested by increased carotid intima-media thickness in rheumatoid arthritis patients. Clin Rheumatol 2017; 36: 1897-1902.

60. Lee, J., et al., Uric acid and coronary heart disease risk: evidence for a role of uric acid in the obesity-insulin resistance syndrome. The normative aging study. Am J Epidemiol 1995; 142: 288-294. 
61. Klein R, Klein BE, Cornoni JC, Maready J, Cassel JC, Tyroler HA. Serum uric acid. Its relationship to coronary heart disease risk factors and cardiovascular disease, Evans County, Georgia. Arch Intern Med 1973; 132: 401-410.

62. Klein BE, Klein R, Lee KE. Components of the metabolic syndrome and risk of cardiovascular disease and diabetes in Beaver Dam. Diabetes Care 2002; 25: 790-794.

63. Kroot EJ, van Gestel AM, Swinkels HL, Albers MM, van de Putte LB, van Riel PL. Chronic comorbidity in patients with early rheumatoid arthritis: a descriptive study. I Rheumatol 2001; 28: 1511-1517.

64. Sattar N, McCarey DW, Capell H, McInnes IB. Explaining how "high-grade" systemic inflammation accelerates vascular risk in rheumatoid arthritis. Circulation 2003; 108: 2957-2963.

65. Symmons DP, Bankhead CR, Harrison BJ, Brennan P, Barrett EM, Scott D, et al. Blood transfusion, smoking, and obesity as risk factors for the development of rheumatoid arthritis: results from a primary care-based incident case-control study in Norfolk, England. Arthritis Rheum 1997; 40: 1955-1961.
66. Crowson CS, Matteson EL, Davis JM 3rd, Gabriel SE. Contribution of obesity to the rise in incidence of rheumatoid arthritis. Arthritis Care Res (Hoboken) 2013; 65: 71-77.

67. Qin B, Liang Y, Yang Zaixing. Response to: 'Body mass index and the risk of rheumatoid arthritis: a systematic review and dose-response meta-analysis'--authors' reply. Arthritis Res Ther 2015; 17: 217.

68. Hannawi S, Marwick TH, Thomas R. Inflammation predicts accelerated brachial arterial wall changes in patients with recent-onset rheumatoid arthritis. Arthritis Res Ther 2009; 11: R51.

69. Ross, R. Atherosclerosis--an inflammatory disease. $N$ Engl J Med 1999; 340: 115-126.

70. Seçil M, Altay C, Gülcü A, Ceçe H, Göktay AY, Dicle O Automated measurement of intima-media thickness of carotid arteries in ultrasonography by computer software. Diagn Interv Radiol 2005; 11: 105-108.

\section{Illustrations, Figures, Photographs}

All figures or photographs should be submitted in a high resolution (minimum 300 DPI) electronic version saved in jpeg or tiff format. Original hard copies of all figures may be requested when necessary. Photographs will be accepted at the discretion of the Editorial Board. All lettering, arrows, or other artwork must be done by an artist or draftsman. If arrows are used please ensure they appear in a different color to the background color, preferably black with a white border, or white with a black border. If arrows distinguish different items on the figure then different arrow styles should be used ie. long, short, wide, narrow. Written informed consent for publication must accompany any photograph in which the subject can be identified. Written copyright permission, from the publishers, must accompany any illustration that has been previously published. 